\title{
Evaluation of the Quality of Beeswax from Different Sources and Rendering Methods
}

\author{
Meseret Gemeda*, Deressa Kebebe \\ Holeta bee research center, Oromia Agricultural Research Institute, Holeta, Ethiopia
}

*Corresponding Author: Meseret Gemeda, Holeta bee research center, Oromia Agricultural Research Institute, Holeta, Ethiopia

\begin{abstract}
Pre- and post-harvest handling and processing of crude beeswax may affect its quality and quantity. Hence, the objective of the present study was to evaluate the quality and quantity of beeswax obtained from different sources and compares the effectiveness of different beeswax extraction methods for rendering quality beeswax. There was significant difference among beeswax sources, extraction methods and interaction between beeswax sources and extraction methods on the yield of beeswax and slum gum $((P<0.05)$. Comparison of beeswax sources revealed that significantly higher beeswax yield of $6.76 \mathrm{~kg}$ source was recorded from crude honey than from comb and sefef with beeswax yield of 2.68 and $2.59 \mathrm{~kg}$, respectively. Among the beeswax extraction methods, submerged method was found significantly superior to manual and solar extraction methods when comb and sefef sources were used, whereas when crude honey was used as a beeswax source, manual and submerged methods were found on par in rendering beeswax. On the other hand, the highest slum gum was recorded from comb and sefef sources particularly when solar extraction method was used. For crude honey source, there was no significant difference among the three extraction methods on slum gum record. The study shown that different beeswax sources and extraction methods had no significant deference on melting, saponification clouding point, acid and ester values. The beeswax obtained in this study has shown similar characteristics with that of beeswax prepared for export purposes in terms of melting point, saponification clouding point, acid and ester values.
\end{abstract}

Keywords: Sefef, Comb, Beeswax, Crude Honey, Rendering Method

\section{INTRODUCTION}

Traditional hives are widely used in developing countries which are mostly in the tropics and subtropics most of the beeswax yield comes from these hives and about 8-10\% of the crude honey is beeswax [1]. Much of the beeswax of the world comes from developing countries and serves as source of cash income and foreign exchange earrings. Beeswax is used for more than 300 purposes and the demand for it never has been satisfied in the local and export market.

Beeswax is a secondary (to honey) but valuable by-product from beekeeping for most beekeepers. It's used for candles, polish and a range of other uses. Additionally, it can be turned into sheets of "foundation", which are thin sheets of wax.

Most of the wax produced now- a-days are used in the manufacture of cosmetics, such as hand and face creams, lipsticks and depilatory wax and many uses. Moreover, the pharmaceutical industry uses the wax in various ointments, for coating pills and suppositories and other miscellaneous industrial products [2].

At world market beeswax commands much higher unit price, (three times more) than honey [4]. In Ethiopia beeswax has been used as one of the important agricultural export commodities for many years. The average annual beeswax export of the country is about 472.2 tons, which is only less than $10 \%$ of the total amount of beeswax produced annually in the country [5].

In many parts of the world much of the beeswax produced by bees that could be harvested by beekeepers is wasted. The beeswax is left or thrown away because beekeepers do not bother to collect and render it into marketable blocks. In less developed countries, beekeepers in distant areas from a large town may have no possibility of selling the beeswax, and no incentive to collect and prepare it. As a result, only one-third, or at most one-half, of the world's production of beeswax comes on to the 
market, the rest being thrown away or lost [6]. Under local condition the main reasons for the wastage of beeswax would be consumption of honey in crude form and discarding the crude beeswax at every crude honey consumer's homes and mainly due to lack of full information on the way of rendering, absence of efficient crude beeswax extraction method and technologies [7].

Even if beeswax is a non-perishable product the way it is processed and handled has a great influence on its quality, quantity and marketing. In the export market the issue of quality products is very important. To become competent both in local and export markets the quality of the beeswax has to be maintained. Processing and marketing of beeswax by producer's cooperative and small-scale processor have been successfully used in many tropical countries. In Ethiopia however the way of handling and processing of crude beeswax may affect its quality and quantity. This is may be due to sources and pre and post-harvest handling conditions. The efficiency of manual beeswax rendering method is very low, only 50\% efficient compared to mechanical presser [7].

The quality of beeswax obtained from tej by product does not seem pure and its color is not light as that of beeswax extracted directly from crude honey. This could be may be due to ingredients used in tej like Gesho (Raminus prinodes) stem and leave, fermentation periods or way of storing of crude beeswax (sefef), the color and the quality of beeswax processed and marketed are varied. Moreover, beeswax obtained from different processing methods affects its quality and quality.

The quality of beeswax is judged from its color, purity and uniformity. Light color beeswax has the greatest value in world market. In Ethiopia, no pervious study examined the quality and quantity of beeswax obtained from different sources and different methods of processing. Therefore, this study was initiated to evaluate the quality and quantity of beeswax obtained from different sources, and to compare the effectiveness of different beeswax extraction methods for rendering pure and quality beeswax.

\section{Materials AND MethodS}

The study was carried out at Holeta Bee Research Center during 2003 and2004 E.C. The experiment was laid out in Randomized Complete Block Design (RCBD) with three replications. Three beeswax sources (comb, sefef and crude honey) and three extraction methods (manual, submerged and solar) were combined in complete factorial arrangement. Crude beeswax such as sefef was collected from tej makers, while comb was obtained from hives that had been broken or crashed and crude honey was attained directly after honey extraction. Ten $\mathrm{kg}$ each of sefef, comb and crude honey were used for three wax extraction methods.

\subsection{Extraction Methods}

\subsubsection{Manual extraction method (simple extraction methods)}

The crude beeswax obtained from different sources were placed separately in clean water and left to soak for 24 hours so that any remaining honey, sheath and water soluble dirt were dissolved in plastic basin or bucket this were done twice. After straining, the wax was melted in sufficient boiling water. Then the wax was poured into sisal and squeezed manually. When the wax ceases to run through, the sisal was twisted and squeezed pulled slowly between two horizontal sticks. The water and wax mixture was leaved to cool and removed the wax block and analyzed for quality, color and the quantity. The left extracted and dried refuses (slum gum) was weighed.

\subsubsection{Submerged wax extraction method}

The beeswax obtained from different sources were placed separately in clean water and left to sock for 24 hours so that any remaining honey was dissolved in plastic bucket. Then the wax was washed and tied up in clean cloth (abujedi) sacks. The tied up wax sack were put in twice its volume of clean water and heated at $70-80^{\circ} \mathrm{C}$ until the wax has melted. The sack is agitated with a stick to cause the wax to float to the top and then pour the melted wax from the boiler. The warm water and wax mixture were poured through a strainer or clean cloth and two sticks were used to squeeze the wax out of cloth. Then, the water and wax mixture were allowed to cool and the wax cake were removed and all the necessary data were collected [8].

\subsubsection{Solar wax extraction method}

The crude beeswax from different sources were melted using solar energy/solar wax extractor at 68 to $70^{\circ} \mathrm{C}$. The sun melts pieces of wax placed on the metal base of a shallow box. Melted beeswax runs 
down the base leaving most of the dross behind through a screen and into a container where it solidifies. The container (mould) in which the wax was to be collected had sloping sides, so that the block of wax was easier to remove and the data of pure beeswax and refuses (slum gum) were collected.

\subsection{Treatment Combinations}

- Crude beeswax (sefef) and manual wax extraction methods

- Crude beeswax (sefef) and submerged wax straining methods

- Crude beeswax (sefef) and solar wax extraction methods

- Crude beeswax comb and manual wax extraction methods

- Crude beeswax comb and submerged wax straining methods

- Crude beeswax comb and solar wax extraction methods

- Crude beeswax from crude honey and manual wax extraction methods

- Crude beeswax from crude honey and submerged wax straining methods

- Crude beeswax from crude honey and solar wax extraction methods

The beeswax obtained from different sources and methods of extraction were evaluated for their color, cleanness and uniformity. The physical and chemical properties that were relevant to beeswax quality like melting point, saponification cloud point, acid value and ester value were tested at Ethiopian Conformity Assessment Enterprise laboratory. The color of pure beeswax extracted from each sources and extraction methods were compared with that of pure beeswax prepared for export. Experimental data were analyzed through analysis of variance using SAS software, and means for each parameter were separated by the least significant difference (LSD) test at $\mathrm{P}=0.05$.

\section{RESULT AND DISCUSSION}

Statistical analysis indicated that there was significant difference among beeswax sources and extraction methods on the yield of beeswax and refuses (slum gum). (Figures 1 and 2), (Table 1and 2). The interaction between beeswax sources and extraction methods was also significant,

Table1: Effect of different beeswax sources and (slum gum) ( $\mathrm{kg}$ )

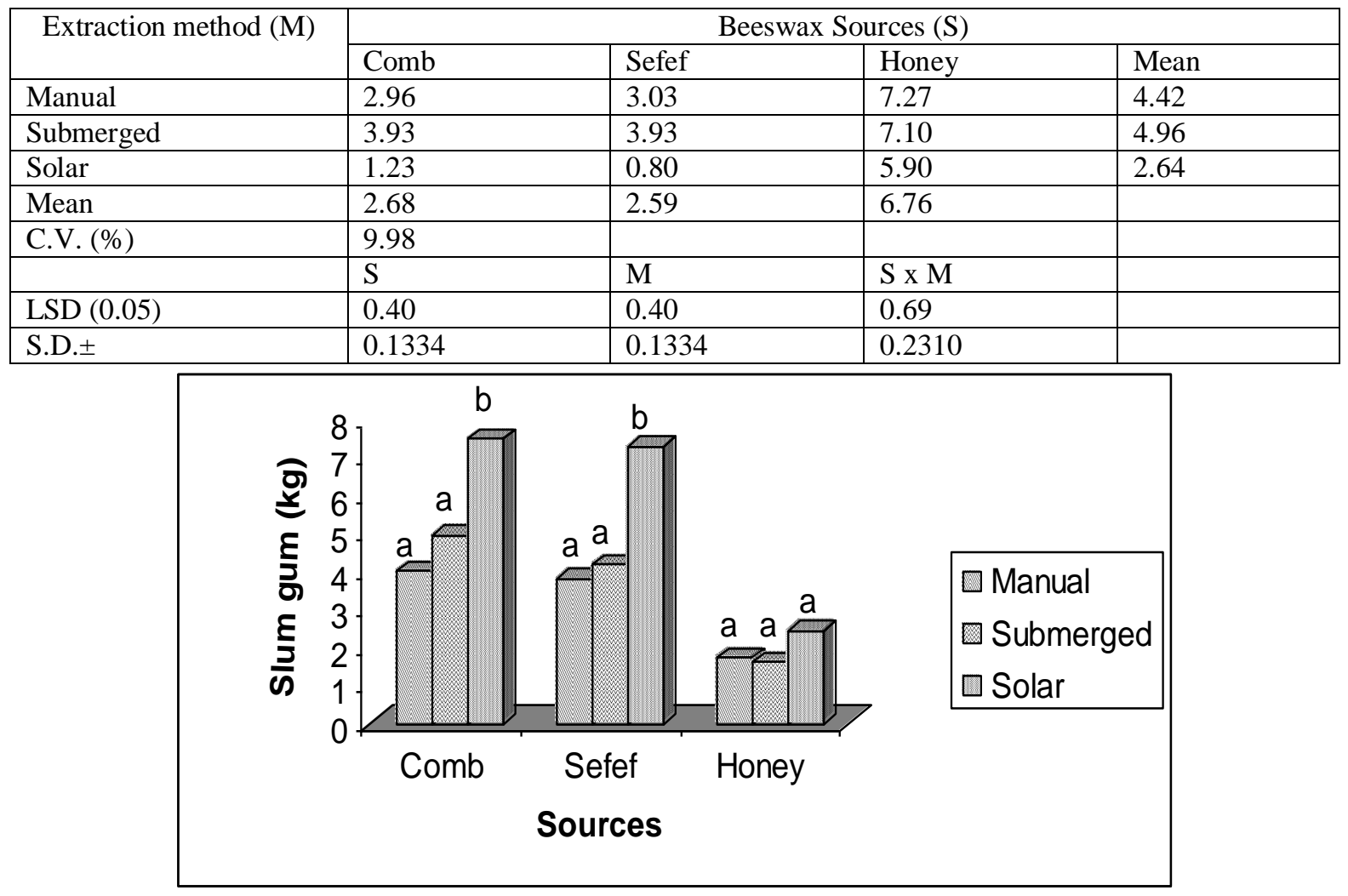

Figure1: Effect of different beeswax sources and rendering methods on beeswax yield ( $k g$ ) 
Table2: Effect of different beeswax sources and rendering methods on refuses rendering methods on beeswax yield $(\mathrm{kg})$

\begin{tabular}{|l|l|l|l|l|}
\hline \multirow{2}{*}{ Extraction method (M) } & \multicolumn{4}{|c|}{ Beeswax Sources (S) } \\
\cline { 2 - 5 } & Comb & Sefef & Honey & Mean \\
\hline Manual & 4.00 & 3.80 & 1.73 & 3.18 \\
\hline Submerged & 4.93 & 4.17 & 1.60 & 3.57 \\
\hline Solar & 7.47 & 7.27 & 2.43 & 5.72 \\
\hline Mean & 5.47 & 5.08 & 1.92 & \\
\hline C.V. $(\%)$ & 17.83 & & & \\
\hline & $\mathrm{S}$ & $\mathrm{M}$ & $\mathrm{S} \times \mathrm{M}$ & \\
\hline LSD $(0.05)$ & 0.74 & 0.74 & 1.28 & \\
\hline S.D. \pm & 0.2469 & 0.2469 & 0.4277 & \\
\hline
\end{tabular}

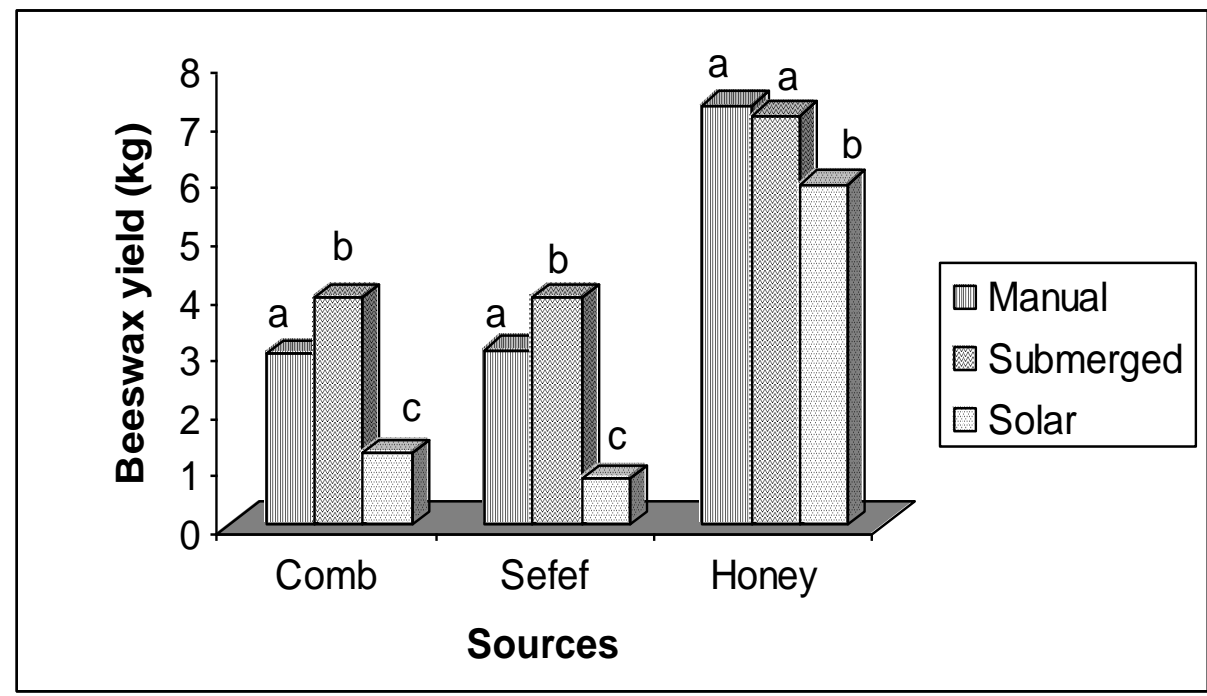

Figure2: Effect of different beeswax sources and rendering methods on slum gum (kg)

Means within the same beeswax sources followed by the same letter are not significantly different $(\mathrm{P}=0.05)$. Means within the same beeswax sources followed by the same letter are not significantly different $(\mathrm{P}=0.05)$. Comparison of beeswax sources revealed that crude honey rendered significantly the highest beeswax and the lowest slum gum as compared to comb and sefef sources. Among the beeswax extraction methods, submerged method was found significantly superior to manual and solar extraction methods when comb and sefef sources were used, whereas when crude honey was used as a beeswax source, manual and submerged methods were found on par in rendering beeswax.

On the other hand, the highest refuses (slum gum) were recorded from comb and sefef sources particularly when solar extraction method was used. In the case of crude honey source there was no significant difference among the three extraction methods on refuses (slum gum) record.

Further, examining quality parameters of the extracted beeswax for color, purity and uniformity revealed that beeswax obtained from crude honey was light in color as compared to that obtained from comb and sefef. One major factor contributing for the deterioration of beeswax is inappropriate storage conditions of honey combs and crude beeswax like sefef and comb.

Beeswax sample obtained from different sources and extraction method were analyzed for melting point, saponification, acid and ester values. Statistical analysis indicated that different beeswax sources and extraction methods had no significant deference on melting, saponification clouding point, acid and ester values of beeswax (table 1,2,3, and 4).

In this study, the value obtained from melting point, saponification clouding point, acid and eater values were ranged in the required standard values of $61-66^{\circ} \mathrm{C}, 85-105,17-24$ and $70-80$ respectively according to Ethiopian Conformity Assessment Enterprise (ECAE) laboratory.

This result is in lined with the American wax importers and refiners Association.

Further, analysis of beeswax prepared for export purpose has shown similar results for melting point, saponification clouding point, acid and eater values as compared to the findings on this study. 
Among the extraction methods manual beeswax extraction method needs four or more-man power to press $10 \mathrm{~kg}$ of melted beeswax. Since the traditional beeswax pressing method is inefficient and contributing for the losses of $47 \%$ of pure beeswax [3], however submerged extraction method is simple and beneficial it can be processed by one or two-man power. A solar wax extractor produces top quality wax. The temperature only needs to rises above 68 to $70^{\circ} \mathrm{C}$ to render beeswax sufficiently and also the extractor has to be turned regularly towards the sun and in cloudy weather or weak sunlight there is no yield at all.

Table3: Effect of different beeswax sources and rendering methods on wax melting point $\left({ }^{O} C\right)$

\begin{tabular}{|l|l|l|l|l|}
\hline \multirow{2}{*}{ Extraction methods } & Beeswax sources & Mean \\
\cline { 2 - 5 } & Comb & Sufef & Crude honey & 63.0 \\
\hline Manual & 63.4 & 61.7 & 64.0 & 63.1 \\
\hline Submerged & 63.6 & 62.5 & 63.2 & 63.6 \\
\hline Solar & 62.9 & 63.6 & 64.3 & \\
\hline Mean & 63.3 & 62.6 & 63.8 & \\
\hline C.V. $(\%)$ & \multicolumn{5}{|l|}{} \\
\hline LSD $(0.05)$ & NS & \multicolumn{5}{|l}{} \\
\hline
\end{tabular}

Table4: Effect of different beeswax sources and rendering methods on wax acid value

\begin{tabular}{|c|c|c|c|c|}
\hline \multirow[t]{2}{*}{ Extraction methods } & \multicolumn{4}{|c|}{ Beeswax sources } \\
\hline & Comb & Sefef & Crude honey & Mean \\
\hline Manual & 16.9 & 17.1 & 17.2 & 17.1 \\
\hline Submerged & 19.9 & 20.1 & 18.6 & 19.5 \\
\hline Solar & 20.6 & 20.9 & 20.2 & 20.5 \\
\hline Mean & 19.1 & 19.4 & 18.6 & \\
\hline C.V. (\%) & \multicolumn{4}{|l|}{3.54} \\
\hline LSD (0.05) & \multicolumn{4}{|l|}{$\mathrm{NS}$} \\
\hline
\end{tabular}

Table5: Effect of different beeswax sources and rendering methods on saponification clouding oint $\left(C^{0}\right)$ of wax

\begin{tabular}{|l|l|l|l|l|}
\hline \multirow{2}{*}{ Extraction methods } & Beeswax sources & \multicolumn{3}{l|}{} \\
\cline { 2 - 5 } & Comb & Sefef & Crude honey & Mean \\
\hline Manual & 86.8 & 94.9 & 99.0 & 93.5 \\
\hline Submerged & 105.2 & 106.7 & 106.7 & 103.6 \\
\hline Solar & 105.0 & 106.9 & 106.9 & \\
\hline Mean & 99.0 & 97.2 & 104 & \\
\hline C.V. (\%) & 11.6 & \multicolumn{4}{l}{} \\
\hline LSD (0.05) & NS & \multicolumn{4}{l|}{} \\
\hline
\end{tabular}

Table6: Effect of different beeswax sources and rendering methods on wax Easter value

\begin{tabular}{|c|c|c|c|c|}
\hline \multirow[t]{2}{*}{ Extraction methods } & \multicolumn{4}{|c|}{ Beeswax sources } \\
\hline & Comb & Sefef & Crude honey & Mean \\
\hline Manual & 69.9 & 77.7 & 81.8 & 76.5 \\
\hline Submerged & 85.3 & 79.0 & 88.1 & 84.1 \\
\hline Solar & 84.4 & 76.9 & 86.8 & 82.7 \\
\hline Mean & 79.9 & 77.9 & 85.6 & \\
\hline C.V. (\%) & \multicolumn{4}{|l|}{14.11} \\
\hline LSD (0.05) & \multicolumn{4}{|l|}{ NS } \\
\hline
\end{tabular}

\section{CONCLUSION AND RECOMMENDATION}

Beeswax extracted from crude beeswax rendered from crud honey has high quantity, quality and purity. Moreover, it has good light color, uniform and to fetch high market value. Among the extraction submerged method was found easy and simple to render high quality beeswax. It is concluded that bee keepers, cooperatives and beeswax processers can use crude honey as beeswax source and submerged extraction method to produce high yield and quality beeswax.

\section{REFERENCES}

[1] Crane, E. 1990. Bees and beekeeping science, practice

[2] Brone, R. 1988. Honey Bees a Guide to Management: The Crowood press Ltd London. pp. 85.

[3] Nuru 1997. Profitability of crude honey processing, $13^{\text {th }}$ ESAP-Proceedings Addis Ababa, Ethiopia, August 25-27, 2004, pp6 
[4] FAO, 1986. Tropical and sub-tropical apiculture, FAO Agricultural services Bulletin 68, Rome, Italy.

[5] Crane, E. 1990. Bees and beekeeping science, practice

[6] Smith F. G. 1960. Beekeeping in the Tropics. Longmans, London, pp. 265

[7] Nuru Adgaba and Eddessa Negera (in press) Profitability of processing crude honey, ESAP $13^{\text {th }}$ annual conference, Addis Ababa, Ethiopia.

[8] Dadant, 1975.The Hive and the Honey Bee, Jorna Printing Campaney. U.S.A., pp 542. And World Resources. Heinemann Newnes and World Resources. HeinemannNewnes, London.UK. pp.434. London.UK.pp. 431.

Citation: Meseret Gemeda, Deressa Kebebe, "Evaluation of the Quality of Beeswax from Different Sources and Rendering Methods" International Journal of Research Studies In Biosciences (Ijrsb), Vol. 7, no. 6, pp. 2025, 2019. http://Dx.Doi.org/10.20431/2349-0365.0706005

Copyright: (c) 2019 Authors. This is an open-access article distributed under the terms of the Creative Commons Attribution License, which permits unrestricted use, distribution, and reproduction in any medium, provided the original author and source are credited. 